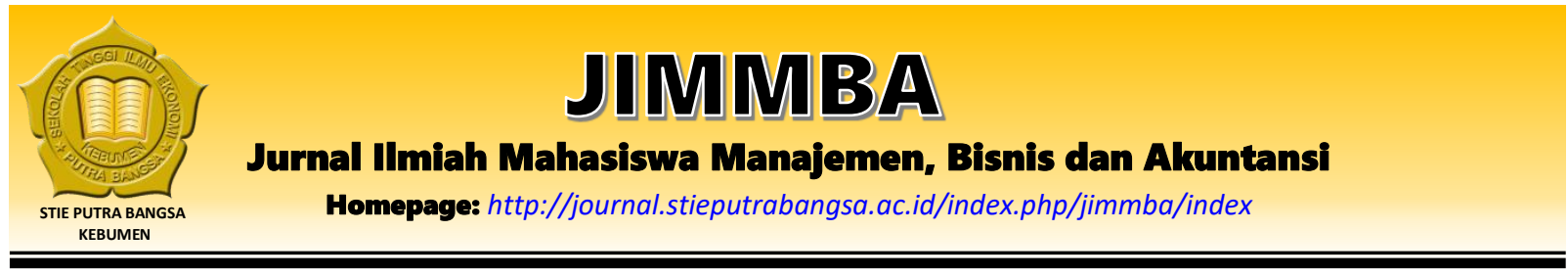

\title{
Pengaruh Perceived Brand Prestige, Product Quality dan Design Product terhadap Keputusan Pembelian Produk Tas Eiger
}

\author{
Ramda Gilang Perdana', Marynta Putri Pratama ${ }^{2}$ \\ 1,2Sekolah Tinggi Ilmu Ekonomi Putra Bangsa \\ Email : gilangfhx@gmail.com¹, maryntaputri@yahoo.com²
}

\begin{tabular}{|c|c|}
\hline ARTICLE INFO & ABSTRACT \\
\hline $\begin{array}{l}\text { Article History: } \\
\text { Received: September } 15^{\text {th }} \\
2020 \\
\text { Accepted: October } 16^{\text {th }} 2020 \\
\text { Published: October } 22^{\text {nd }} 2020 \\
\text { Keywords: } \\
\text { Perceived Brand Prestige, } \\
\text { Product Quality, Design } \\
\text { Product, Purchasing } \\
\text { Decisions }\end{array}$ & $\begin{array}{l}\text { Penelitian ini bertujuan untuk mengetahui pengaruh Perceived Brand } \\
\text { Prestige, Product Quality dan Design Product terhadap keputusan } \\
\text { pembelian produk tas Eiger. Populasi dalam penelitian ini adalah } \\
\text { masyarakat di Kabupaten Kebumen yang pernah melakukan } \\
\text { pembelian dan pengguna produk tas merek Eiger. Sampel penelitian } \\
\text { sebanyak } 100 \text { responden dengan metode purposive sampling. Teknik } \\
\text { Analisis yang digunakan dalam penelitian ini analisis kualitatif dan } \\
\text { analisis kuantitatif. Analisis data menggunakan analisis regresi } \\
\text { linear berganda (skala likert) } 4 \text { dengan program SPSS for windows } 25 \text {. } \\
\text { Hasil penelitian ini menunjukkan product quality dan design product } \\
\text { berpengaruh signifikan terhadap keputusan pembelian, sedangkan } \\
\text { perceived brand prestige tidak berpengaruh terhadap keputusan } \\
\text { pembelian pada produk tas Eiger di Kabupaten Kebumen. Hasil } \\
\text { pengujian ini menunjukan bahwa nilai Adjusted } R \text { Square sebesar } \\
0,575 \text { artinya sebesar } 57,5 \% \text { variabel keputusan pembelian dapat } \\
\text { dijelaskan oleh variabel perceived brand prestige, product quality dan } \\
\text { design product, sedangkan sebesar } 42,5 \% \text { dapat dijelaskan. }\end{array}$ \\
\hline
\end{tabular}

\section{Pendahuluan}

Kehidupan masyarakat saat ini terkhusus remaja memiliki hobi yaitu berkegiatan di alam bebas atau outdoor, tentunya mereka para remaja berlomba untuk memiliki perlengkapan yang sesuai tranding kegiatan alam bebas tersebut maupun untuk gaya hidup sehari-hari. Fenomena ini dapat disebut dengan gaya hidup (lifestyle) baru dalam masyarakat.

Produk fashion outdoor yang dilihat dari sisi kualitas salah satunya tas. Tas merupakan produk yang termasuk dalam produk mode, tas memiliki perkembangan yang cepat sesuai dengan keadaan masyarakat yang dinamis. Selain fungsi tas sebagai peralatan membawa barang untuk berkegiatan sehari-hari, tas juga merupakan pelengkap penunjang berkegaitan di alam bebas (outdoor). Sehingga banyak jenis dan model tas yang diperuntukkan sesuai fungsi dan kegunaan. Salah satu produsen penyedia produk tas untuk sehari-hari maupun untuk outdoor yang memiliki daya saing tinggi terhadap pesaing sejenis adalah Eiger. Eiger adalah produk peralatan kegiatan alam bebas yang diproduksi oleh PT. Eigerindo Multi Produk Industri dan didirikan pada tahun 1993. Eiger mampu mendobrak pasar dari industri 
peralatan outdoor di Indonesia. Ketika produk Eiger belum muncul, pasar peralatan outdoor seolah tidak berkembang akibat kurangnya inovasi pada produk yang beredar di pasar saat itu. Produk Eiger kerap dikaitkan dengan produk alat mendaki karena sebagian besar produk dari Eiger yaitu peralatan mendaki. Eiger berusaha berinovasi untuk mengubah image dengan membuat produk fashion outdoor salah satunya produk fashion bag outdoor yang diproduksi bagi konsumen kalangan umum yang tidak sepenuhnya dalam bidang penggiat alam, tetapi dengan demikian Eiger tidak menghilangkan sifat estetika yang diterapkan dalam produk tas tersebut dengan kualitas, teknologi, ketahanan dan modern serta mewujudkan desain yang kasual dan stylis.

Terobosan ini mampu membuka pasar menjadi lebih luas dengan menjangkau seluruh konsumen secara umum. Eiger yang awalnya hanya digunakan di kegiatan alam bebas, tetapi inovasi yang dilakukan Eiger dapat mengubah pandangan tersebut. Eiger beranggapan bahwa inovasi ini dapat memperluas brand menuju kalangan masyarakat umum yang tidak hanya mengenal dunia outdoor, serta dapat meningkatkan pembelian produk dari brand Eiger.

Menurut Kotler dan Amstrong (2012:188) dalam Hanjaya (2016) menyatakan bahwa keputusan pembelian adalah tahapan dalam proses pengambilan keputusan pembelian dimana konsumen benar-benar membeli. Mengingat begitu pentingnya keputusan konsumen dalam membeli, perusahaan dituntut untuk terus berupaya melakukan strategi-strategi pemasaran dan produk dari segi persaingan. Sedangkan proses pengambilan keputusan pembelian memiliki lima tahap yaitu: mengenal kebutuhan, pencarian informasi, evaluasi alternatif, keputusan membeli, perilaku pasca pembelian (Kotler \& Amstrong 2001:222).

Berdasarkan hasil observasi banyak faktor yang mempengaruhi masyarakat dalam menentukan keputusan pembelian mereka pada pembelian tas brand Eiger. Guna mendukung variabel apa saja yang mempengaruhi keputusan pembelian tas brand Eiger di Kabupaten Kebumen, penulis melakukan sebuah observasi mini riset kepada pengguna tas Eiger di Kabupaten Kebumen dengan mengambil sampel sebanyak 30 responden, dengan hasil sebagai berikut:

Tabel 1. Faktor yang mempengaruhi Pembelian tas Eiger di Kebumen

\begin{tabular}{llc}
\hline No & Variabel & Jumlah Responden \\
\hline 1 & Perceived Brand Prestige & 5 \\
2 & Product Quality & 18 \\
3 & Design Product & 5 \\
4 & Lain-lain & 2 \\
\hline
\end{tabular}

Sumber: Data primer diolah (2019)

Dari tabel 1 menunjukkan hasil observasi awal yang dilakukan penulis yaitu faktor-faktor yang mempengaruhi pembelian yang terdiri dari 30 responden yang dijadikan sebagai sempel sementara. Berdasarkan observasi awal menunjukkan bahwa pengguna produk tas Eiger yang mereka pakai di sebabkan oleh faktor yang paling besar yaitu Quality Product sebesar 60\% yang menjadi alasan konsumen dikarenakan mereka merasakan kualitas dari tas merek Eiger mampu memenuhi fungsi dan kegunaan yang tinggi sebagai barang yang memiliki day tahan 
untuk membawa barang serta memiliki keawetan yang lama, dan mereka sebagai pengguna mengakui bahwa produk dari brand Eiger memenuhi hal itu. Faktor kedua yang menjadi alasan konsumen untuk membeli adalah Brand Prestige sebesar 16,7\%, mereka berasumsi bahwa mengenakan tas produk Eiger Adventure menjadikan dirinya menambah percaya diri, terkesan berstatus tinggi dengan menggunakan produk brand Eiger tersebut karena tingkat image dalam pengguna produk outdoor lain brand Eiger lebih unggul dari segi image kualitas dan harga yang relatif mahal. Faktor ketiga yang menjadi alasan konsumen untuk membeli adalah Design Product sebesar 16,7\%, mereka menilai bahwa produk Eiger memiliki penampilan yang estetik dan warna yang menarik sesuai tren ala - ala outdoor masa kini.

Menurut Vigneron dan Johnson (1999) menyatakan terdapat lima faktor yang umum digunakan untuk mengukur brand prestige. Faktor pertama yang menjadikan merek tersebut dianggap prestige adalah perceived quality value, merek dianggap memberikan persepi kualitas yang baik. Kualitas dari produk tentunya berbeda berdasarkan bagaimana persepsi konsumen melihat dari sudut pandang individual. Faktor kedua yang menjadi dimensi brand prestige adalah perceived emotional value. Menurut Hirschman et al. dalam Vigneron dan Johnson (1999), beberapa barang dan layanan tertentu memiliki nilai emosional yang menjadi kelebihan dari kegunaan awal barang tersebut. Faktor ketiga yang menjadi dimensi brand prestige adalah perceived social value. Belk (1988) mengatakan bahwa orang-orang yang ingin memiliki sebuah merek yang prestige beranggapan bahwa merek sebagai simbol yang menandakan identitas grup atau komunitas mereka. Selain tiga dimensi diatas, dimensi ke empat dari brand prestige adalah perceived unique value. Penelitian yang dilakukan oleh Vigneron dan Johnson (1999) membuktikan bahwa apabila konsumen melihat produk dari merek yang prestige dan produk bermerek tersebut diproduksi dalam jumlah sedikit, maka hal tersebut akan mempengaruhi minat beli mereka. Dimensi terakhir dari brand prestige adalah perceived conspicuous value. Dimensi ini mengukur tentang seberapa sadar konsumen akan merek yang tinggi. Permintaan akan sebuah produk yang berkualitas juga membuat perusahaan yang berada dibidang fashion outdoor berlomba-lomba untuk meningkatkan kualitas produk mereka demi mempertahankan image produk yang mereka miliki.

Kualitas Produk merupakan kemampuan suatu produk untuk melaksanakan fungsinya, meliputi keandalan, daya tahan, ketepatan, kemudahan operasi serta perbaikan produk. Kualitas produk adalah suatu bentuk dengan nilai kepuasan yang kompleks (Hidayat, 2009). Suatu barang dapat dinilai bagus atau tidaknya dari seluruh kemampuan yang dapat dilakukan oleh suatu produk, semakin produk mampu memberikan kinerja yang sesuai dengan ekspektasi penggunanya disitulah barang dinilai bagus. Kualitas produk didefinisikan sebagai evaluasi menyeluruh pelanggan atas kebaikan kinerja barang atau jasa. (Mowen dan Minor, 2002).

Desain produk adalah totalitas keistemewaan yang mempengaruhi penampilan dan fungsi suatu produk dari segi kebutuhan pelanggan. Dengan semakin ketatnya persaingan, desain akan menjadi salah satu cara yang paling ampuh untuk mendiferensiasikan dan memposisikan produk. Menurut Stanton (1995) Desain produk merupakan salah satu aspek pembentuk citra produk. Perusahaan juga makin menyadari pentingnya nilai pemasaran dari desain produk, terutama desain penampilannya. Dua faktor yang menyangkut desain produk adalah warna dan kualitas produk. Menurut. Durvasula et al pada Mas'ud (2004:443, dalam 
Enrico, 2009) mengemukakan indikator untuk mengukur desain produk adalah dengan model terbaru, gaya yang menarik, variasi dan uptodate. Berikut adalah data Top Brand Index kategori Tas 2016-2019 yang diperoleh dari topbrand-award.com.

Tabel 2. Data Top Brand Award (TBI) Tahun 2016-2019

\begin{tabular}{l|r|l|r|l|l|l|r}
\hline \multicolumn{2}{c}{ Tahun 2016} & \multicolumn{2}{c}{ Tahun 2017 } & \multicolumn{2}{c}{ Tahun 2018 } & \multicolumn{2}{c}{ Tahun 2019 } \\
\hline \multicolumn{1}{c}{ Merek } & TBI & Merek & TBI & Merek & TBI & Merek & TBI \\
\hline Polo & $21.9 \%$ & Polo & $16.2 \%$ & Polo & $20.1 \%$ & Eiger & $19.1 \%$ \\
& & & & & & & \\
Palazzo & $15.0 \%$ & Eiger & $16.1 \%$ & Eiger & $15.6 \%$ & Polo & $18.6 \%$ \\
& & & & & & & \\
Eiger & $14.9 \%$ & Palazzo & $14.0 \%$ & Palazzo & $13.1 \%$ & Palazzo & $16.8 \%$ \\
Export & $7.1 \%$ & Bodypack & $5.6 \%$ & Targus & $4.8 \%$ & Targus & $5.9 \%$ \\
& & & & Samsonite & $2.9 \%$ & Samsonite & $4.9 \%$ \\
\hline
\end{tabular}

Sumber: Data primer diolah (2019)

Berdasarkan tabel 2 menunjukkan bahwa merek Eiger mengalami peningkatan di Top Brand Index di tiap tahunnya dimana di tahun 2016 Eiger menduduki Top Brand Index urutan ketiga yaitu $14.0 \%$, lalu pada tahun 2017 mengalami peningkatan yaitu menjadi peringkat sebesar 16.1\%, lalu pada tahun 2019 Eiger mampu menduduki urutan pertama di Top Brand Index yaitu 19.1\%. Hal ini dapat mengindikasikan bahwa merek Eiger dari tiap tahunnya selalu diminati masyarakat dengan banyak keunggulannya yang menjadi pilihan utama serta mampu menyalip merek-merek lain.

\section{Kajian Teori dan Telaah Literatur}

\section{Keputusan pembelian}

Menurut Swastha dan Irawan (2008:105) keputusan pembelian adalah pemahaman konsumen tentang keinginan dan kebutuhan akan suatu produk dengan menilai dari sumber-sumber yang ada dengan menetapkan tujuan pembelian serta mengidentifikasi alternatif sehingga pengambil keputusan untuk membeli yang disertai perilaku setelah melakukan pembelian. Kotler dan Keller (2008:240) menyatakan bahwa keputusan pembelian adalah keputusan konsumen mengenai preferensi atas merek-merek yang ada di dalam kumpulan pilihan.

\section{Perceived Brand Prestige}

Menurut Erdogmus dan Budeyri-Turan (2012) brand prestige didefinisikan sebagai status yang relative tinggi yang berkaitan dengan posisi sebuah merek yang dapat meningkatkan status pemakainya. Sedangkan menurut Dubois dan Czellar dalam Choi et al (2011) dalam kategori produk, kriteria penting dari sebuah merek untuk dapat dinilai sebagai merek yang prestige adalah keunikan dari merek tersebut, yang dapat berupa atribut tertentu atau kualitas produk tersebut dan proses pembuatannya.

\section{Product Quality}

Menurut Kotler dan Amstrong (2005), kualitas produk merupakan keseluruhan ciri dari suatu produk atau pelayanan pada kemampuan untuk memuaskan kebutuhan yang dinyatakan atau tersirat. Sedangkan menurut Kotler dan Amstrong (2008) menyatakan bahwa kualitas produk merupakan kemampuan suatu produk untuk melakukan fungsi-fungsinya yang 
meliputi daya tahan, keandalan, ketepatan, kemudahan, operasi dan perbaikan serta atribut lainnya. Bila suatu produk telah dapat menjalankan fungsi-fungsinya dapat dikatakan sebagai produk yang memiliki kualitas yang baik.

\section{Design Product}

Menurut Kotler dan Keller (2009) desain adalah totalitas fitur yang mempengaruhi tampilan, rasa, dan fungsi produk berdasarkan kebutuhan pelanggan. Inovasi desain dalam produk mampu mempengaruhi segala hal yang ditambahkan atau dikurangkan pada suatu barang atau produk sehingga konsumen dapat merasakan produk sesuai dengan keinginannya. Desain sangata penting terutama dalam pembuatan dan pemasaran jasa eceran, busana, barang kemasan, dan peralatan tahan lama. Desainer harus mengetahui kebutuhan desain yang saat ini menjadi rasa ketertarikan sesuai selera saat ini sebagai tolak ukur keinginan konsumen.

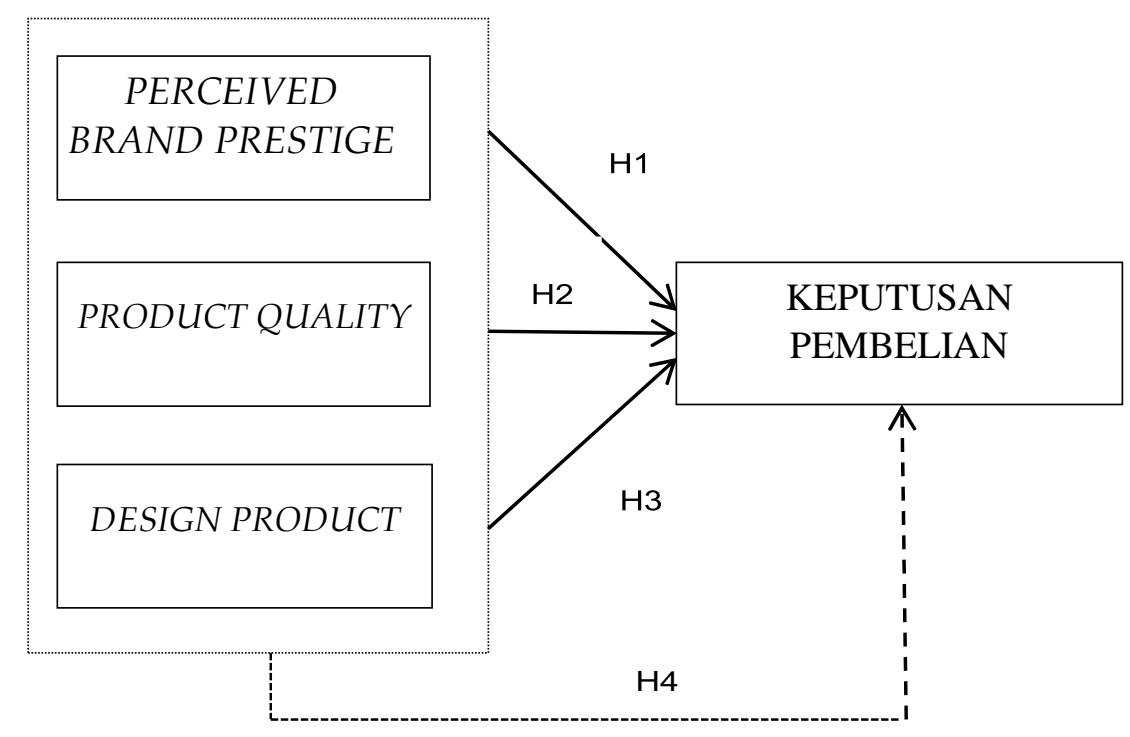

Gambar 1. Model Penelitian

\section{Metode Penelitian}

Objek penelitian ini, penulis memberi spesifikasi Pengaruh Perceived Brand Prestige, Product Quality dan Desain Produk (sebagai variabel independen) terhadap Keputusan Pembelian (sebagai variabel dependen). Subyek dalam penelitian ini adalah semua konsumen yang sudah membeli produk Tas Eiger berbagai jenis dan seri dari merek Eiger di Kabupaten Kebumen. Sedangkan jumlah sampel yang digunakan dalam penelitian ini adalah 100 responden. Metode pengambilan sampel dengan menggunakan teknik purposive sampling, teknik penentuan sampel dengan pertimbangan tertentu (Sugiyono, 2010). Kriteria atau syarat sampel yang dijadikan responden dalam penelitian ini adalah masyarakat di Kabupeten Kebumen yang berusia 17-35 yang pernah melakukan pembelian dan memakai tas brand Eiger. Teknik analisis data yang digunakan antara lain analisis kualitatif dan analisis kuantitatif yang terdiri dari uji validitas, uji reliabilitas, uji t, uji $\mathrm{F}$, analisis regresi linier berganda (skala likert) 4. Data dianalisis dengan bantuan program SPSS Release 25 for Windows. 


\section{Hasil dan Pembahasan}

\section{Uji validitas}

Tabel 3. Hasil Uji Validitas Variabel Perceived Brand Prestige

\begin{tabular}{lllcc}
\hline Butir & r hitung & r tabel & Signifikan & Keterangan \\
\hline X1.1 & 0,723 & 0,1966 & 0,000 & Valid \\
X1.2 & 0,676 & 0,1966 & 0,000 & Valid \\
X1.3 & 0,745 & 0,1966 & 0,000 & Valid \\
X1.4 & 0,671 & 0,1966 & 0,000 & Valid \\
X1.5 & 0,590 & 0,1966 & 0,000 & Valid \\
\hline
\end{tabular}

Sumber: Data primer diolah, 2020

Berdasarkan tabel 3 di atas menunjukkan semua instrumen perceived brand prestige dinyatakan valid karena rhitung $>$ rtabel. $(0,1966)$ dan signifikan $<0,05$ sehingga kelima item butir pertanyaan variabel perceived brand prestige pada kuesioner dinyatakan valid (sah).

Tabel 4. Hasil Uji Validitas Variabel Product Quality

\begin{tabular}{lllrc}
\hline Butir & r hitung & r tabel & Signifikan & Keterangan \\
\hline X2.1 & 0,615 & 0,1966 & 0,000 & Valid \\
X2.2 & 0,557 & 0,1966 & 0,000 & Valid \\
X2.3 & 0,692 & 0,1966 & 0,000 & Valid \\
X2.4 & 0,636 & 0,1966 & 0,000 & Valid \\
X2.5 & 0,632 & 0,1966 & 0,000 & Valid \\
X2.6 & 0,682 & 0,1966 & 0,000 & Valid \\
\hline
\end{tabular}

Sumber : Data primer diolah, 2020

Berdasarkan tabel 4 di atas menunjukkan semua instrumen product quality dinyatakan valid karena rhitung $>$ rtabel. $(0,1966)$ dan signifikan $<0,05$ sehingga ketiga item butir pertanyaan variabel product quality pada kuesioner dinyatakan valid (sah).

Tabel 5. Hasil Uji Validitas Variabel Design Product

\begin{tabular}{lllrr}
\hline Butir & r hitung & r tabel & Signifikan & Keterangan \\
\hline X2.1 & 0,642 & 0,1966 & 0,000 & Valid \\
X2.2 & 0,604 & 0,1966 & 0,000 & Valid \\
X2.3 & 0,715 & 0,1966 & 0,000 & Valid \\
X2.4 & 0,726 & 0,1966 & 0,000 & Valid \\
X2.5 & 0,675 & 0,1966 & 0,000 & Valid \\
X2.6 & 0,653 & 0,1966 & 0,000 & Valid \\
\hline
\end{tabular}

Sumber : Data primer diolah, 2020

Berdasarkan tabel 5 di atas menunjukkan semua instrumen design product dinyatakan valid karena rhitung $>$ rtabel. $(0,1966)$ dan signifikan $<0,05$ sehingga keenam item butir pertanyaan variabel design product pada kuesioner dinyatakan valid (sah). 
Tabel 6. Hasil Uji Validitas Variabel Keputusan Pembelian

\begin{tabular}{lllll}
\hline Butir & r hitung & r tabel & Signifikan & Keterangan \\
\hline Y2.1 & 0,619 & 0,1966 & 0,000 & Valid \\
Y2.2 & 0,625 & 0,1966 & 0,000 & Valid \\
Y2.3 & 0,730 & 0,1966 & 0,000 & Valid \\
Y2.4 & 0,737 & 0,1966 & 0,000 & Valid \\
Y2.5 & 0,664 & 0,1966 & 0,000 & Valid \\
\hline
\end{tabular}

Berdasarkan tabel 6 di atas menunjukkan semua instrumen keputusan pembelian dinyatakan valid karena rhitung $>$ rtabel. $(0,1966)$ dan signifikan $<0,05$ sehingga kelima item butir pertanyaan variabel keputusan pembelian pada kuesioner dinyatakan valid (sah).

\section{Pengujian Reliabilitas}

Tabel 7.Hasil Uji Reliabilitas

\begin{tabular}{lllll}
\hline No & Variabel & \multicolumn{2}{c}{ cronbach's Batas } & Keterangan \\
& & alpha & Penerimaan \\
\hline 1 & Perceived Brand Prestige & 0,713 & 0,60 & Reliabel \\
2 & Product Quality & 0,701 & 0,60 & Reliabel \\
3 & Design Product & 0,751 & 0,60 & Reliabel \\
4 & Keputusan Pembelian & 0,696 & 0,60 & Reliabel \\
Sumber: Data primer diolah, 2020 & & &
\end{tabular}

Berdasarkan tabel 7 dapat dijelaskan bahwa seluruh pertanyaan yang digunakan dalam masing-masing variabel dinyatakan reliabel (andal) dikarenakan nilai Alpha Cronbach's pada masing-masing variabel lebih besar dari batas penerimaan yaitu 0,60.

\section{Uji Hipotesis}

\section{Uji Parsial (Uji-t)}

Tabel 8. Hasil Uji Parsial (Uji t)

\begin{tabular}{|c|c|c|c|c|c|}
\hline \multicolumn{6}{|c|}{ Coefficients $^{a}$} \\
\hline \multirow[b]{2}{*}{ Model } & \multicolumn{2}{|c|}{$\begin{array}{c}\text { Unstandardized } \\
\text { Coefficients }\end{array}$} & \multirow{2}{*}{$\begin{array}{l}\text { Standardized } \\
\text { Coefficients } \\
\text { Beta }\end{array}$} & \multirow[b]{2}{*}{$\mathrm{T}$} & \multirow[b]{2}{*}{ Sig. } \\
\hline & B & Std. Error & & & \\
\hline $1 \quad$ (Constant) & 3.779 & 1.156 & & 3.270 & .001 \\
\hline $\begin{array}{l}\text { Perceived_Bran } \\
\text { d_Prestige }\end{array}$ & .018 & .068 & .021 & .264 & .793 \\
\hline Product_Qualiti & .443 & .069 & .559 & 6.432 & .000 \\
\hline Desain_Produk & .201 & .068 & .265 & 2.972 & .004 \\
\hline
\end{tabular}

a. Dependent Variable: Keputusan Pembelian

Sumber: Data primer diolah, 2020. 
Berdasarkan tabel 8 diatas, taraf signifikan (a) sebesar 5\% (two tailed) dengan derajat kebebasan $(\mathrm{df}=\mathrm{n}-\mathrm{k})=100-4=96$, maka diperoleh nilai ttabel sebesar 1.98498 .

\section{a. Pengaruh perceived brand prestige terhadap keputusan pembelian}

Hasil uji t pada tabel 8 diatas menunjukkan nilai thitung sebesar 0,264 < ttabel sebesar 1.984 dan nilai signifikansi sebesar 0,793 > 0,05 sehingga dapat disimpulkan bahwa variabel perceived brand prestige tidak berpengaruh terhadap variabel keputusan pembelian atau dapat diartikan bahwa hipotesis (H1) ditolak.

\section{b. Pengaruh product quality terhadap keputusan pembelian}

Hasil uji t pada tabel 8 diatas menunjukkan nilai thitung sebesar 6,432 >ttabel sebesar 1.984 dan nilai signifikansi sebesar 0,000 < 0,05 sehingga dapat disimpulkan bahwa variabel product quality berpengaruh secara signifikan terhadap variabel keputusan pembelian atau dapat diartikan bahwa hipotesis $(\mathrm{H} 2)$ diterima.

\section{c. Pengaruh design product terhadap keputusan pembelian}

Hasil uji t pada tabel 8 diatas menunjukkan nilai thitung sebesar 2,972 $>$ ttabel sebesar 1.984 dan nilai signifikansi sebesar 0,004 < 0,05 sehingga dapat disimpulkan bahwa variabel design product berpengaruh secara signifikan terhadap variabel keputusan pembelian atau dapat diartikan bahwa hipotesis $(\mathrm{H} 3)$ diterima.

\section{Penutup dan Saran}

\section{Simpulan}

Penelitian ini menguji pengaruh perceived brand prestige, product quality, design product. Adapun yang menjadi subyek dalam penelitian ini adalah konsumen produk tas brand Eiger di Kabupaten Kebumen. Berdasarkan hasil analisis data dengan menggunakan alat analisis regresi linier berganda dan pembahasan hasil peneitian yang telah dikemukakan pada bab sebelumnya, dapat disimpulkan beberapa hal dalam penelitian ini sebagai berikut:

1. Berdasarkan hasil penelitian menunjukan perceived brand prestige tidak berpengaruh terhadap keputusan pembelian, artinya bahwa tinggi rendahnya tingkat prestige pada tas brand Eiger tidak dapat mempengaruhi keputusan pembelian. Oleh karena itu perusahaan harus berinovasi lebih agar konsumen merasa bangga untuk menggunakan produk tas brand Eiger itu sendiri, dengan cara memproduksi produk-produk tas Eiger yang memiliki nilai jual tinggi, tetapi bukan hanya daya tarik melainkan mempertahankan harga tinggi sesuai kesadaran konsumen terhadap kualitas yang mumpuni.

2. Berdasarkan hasil penelitian ini menunjukkan bahwa product quality mempunyai pengaruh yang signnifikan terhadap keputusan pembelian pada produk tas brand Eiger di Kabupaten Kebumen. Artinya nilai kualitas dalam penelitian ini sangat berpengaruh terhadap keputusan pembelian pada produk tas brand Eiger di Kabupaten Kebumen dengan dibuktikannya hasil diatas, bahwa kualitas yang baik dan mumpuni akan berdampak pada keputusan pembelian produk tas (semua tipe dan seri) brand Eiger di Kabupaten Kebumen, begitu juga sebaliknya jika kualitas yang kurang baik akan berakibat pada penurunan pembelian produk tas brand Eiger tersebut. 
3. Berdasarkan hasil penelitian ini menunjukkan bahwa design product mempunyai pengaruh yang signifikan terhadap produk tas brand Eiger di Kabupaten Kebumen. Artinya tingkat desain dalam penelitian ini sangat berpengaruh terhadap keputusan pembelian produk tas brand Eiger di Kabupaten Kebumen dengan dibuktikannya hasil diatas, bahwa design product yang baik akan berdampak positif pada keputusan pembelian produk tas brand Eiger di Kabupaten Kebumen begitu juga sebaliknya desain produk yang kurang baik akan berakibat pada penurunan pembelian produk tas brand Eiger.

4. Berdasarkan hasil penelitian ini menunjukkan bahwa perceived brand prestige tidak berpengaruh terhadap keputusan pembelian produk tas brand Eiger di Kabupaten Kebumen. Sedangkan product quality dan design product berpengaruh signifikan terhadap keputusan pembelian produk tas brand Eiger di Kabupaten Kebumen. Artinya peran variabel product quality dan design product sangat berpengaruh dalam pertimbangan konsumen untuk membeli dan menggunakan tas brand Eiger, sedangkan variabel perceived brand prestige perlu diperbaiki secara sifat dan produknya itu sendiri agar ketiga variabel tersebut saling berpengaruh terhadap keputusan pembelian pada produk tas brand Eiger di Kabupaten Kebumen.

5. Berdasarkan hasil analisis variabel perceived brand prestige, product quality dan design product variabel yang berpengaruh paling dominan terhadap keputusan pembelian yaitu variabel product quality, variabel yang berpengaruh kedua yaitu design product dan variabel yang berpengaruh paling kecil yaitu variabel perceived brand prestige.

\section{Keterbatasan}

Penelitian ini memiliki beberapa keterbatasan, yaitu sebagai berikut:

1. Penelitian ini hanya terbatas pada variabel perceived brand prestige, product quality dan design product, dan keputusan pembelian produk tas brand Eiger di Kabupaten Kebumen.

2. Pada penelitian ini jumlah sampel yang digunakan relative sedikit yaitu 100 responden, sehingga hasil penelitian ini tidak dapat digeneralisasikan karena penelitian ini hanya dibatasi pada masyarakat Kabupaten Kebumen yang sudah membeli dan menggunakan tas merek Eiger. Keterbatasan yang melekat pada metode penyebaran angket atau kuesioner yaitu peneliti tidak dapat mengontrol jawaban responden, dimana responden bisa saja tidak jujur dalam menjawab setiap pertanyaan yang disajikan dalam kuesioner.

3. Variabel yang diteliti masih dirasa belum cukup untuk mengukur faktor-faktor yang mempengaruhi keputusan pembelian, sehingga untuk penelitian lebih lanjut perlu menambahkan variabel lain yang dapat mempengaruhi keputusan pembelian seperti harga, lifestyle, kesadaran merek, loyalitas merek, citra merek dan lain-lain.

\section{Implikasi Implikasi Praktis}

Berdasarkan hasil penelitian yang dilakukan menunjukkan bahwa perceived brand prestige tidak berpengaruh terhadap keputusan pembelian, sedangkan product quality dan design 
product berpengaruh signifikan terhadap keputusan pembelian tas Eiger di Kabupaten Kebumen, oleh karena itu implikasi praktis dari penelitian ini adalah :

1. Bagi perusahaan diharap untuk memperhatikan faktor perceived brand prestige pada produk tas brand Eiger di Kabupaten Kebumen. Karena nilai prestis yang baik dapat meningkatkan daya tarik keputusan pembelian pada produk tas brand Eiger di Kabupaten Kebumen. Nilai prestige yang baik yang diterapkan pada perusahaan akan meningkatkan daya jual produk tas Eiger seperti persepsi nilai kualitas, persepsi nilai unik, persepsi nilai sosial, persepsi nilai emosional pada produk itu sendiri agar segala aspek yang terdapat pada perceived brand prestige dapat mempengaruhi keputusan pembelian pada produk tas brand Eiger di Kabupaten Kebumen.

2. Bagi perusahaan diharap untuk memperhatikan faktor product quality pada produk tas brand Eiger di Kabupaten Kebumen. Karena faktor kualitas produk yang baik dapat meningkatkan keputusan pembelian pada produk tas brand Eiger di Kabupaten Kebumen. Kualitas produk yang baik yang diterapkan pada perusahaan akan meningkatkan keputusan pembelian produk tas Eiger seperti kinerja produk, fitur, kehandalan, kesesuaian, daya tahan dan estetika pada produk itu sendiri agar segala aspek yang terdapat pada product quality dapat mempengaruhi keputusan pembelian pada produk tas brand Eiger di Kabupaten Kebumen.

Bagi perusahaan diharap untuk memperhatikan faktor design product pada produk tas brand Eiger di Kabupaten Kebumen. Karena faktor desain produk yang baik dan menarik dapat meningkatkan keputusan pembelian pada produk tas brand Eiger di Kabupaten Kebumen. Design product yang baik yang diterapkan pada perusahaan akan meningkatkan keputusan pembelian produk tas Eiger seperti model, ciri-ciri, mutu kesesuaian, tahan lama, tahan uji dan kemudahan dalam perbaikan pada produk itu sendiri agar segala aspek yang terdapat pada design product dapat mempengaruhi keputusan pembelian pada produk tas brand Eiger di Kabupaten Kebumen.

\section{Implikasi Teoritis}

Hasil penelitian ini memberikan implikasi bagi penelitian selanjutnya, yaitu sebagai berikut:

1. Peneliti memberikan saran bagi penelitian selanjutnya untuk dapat memberikan hasil yang lebih baik lagi dan disarankan untuk menambahkan atau mencari variabel lain selain yang ada pada model penelitian.

2. Perceived brand prestige tidak dapat berpengaruh terhadap keputusan pembelian, sehingga disarankan untuk penelitian selanjutnya mengganti variabel tersebut, dengan variabel lainnya.

3. Jumlah responden dalam penelitian ini sebanyak 100 orang, sehingga responden yang ada sangat terbatas, maka disarankan untuk penelitian selanjutnya menambah jumlah responden agar hasil penelitiannya lebih baik lagi 


\section{Referensi}

Assauri, S. (2012). Manajemen Pemasaran. Jakarta: PT Raja Grapindo.

Azany, F., \& Mudiantono, M. (2014). Analisis Pengaruh Desain Produk, Motivasi Konsumen Dan Citra Merek Terhadap Keputusan Pembelian Sepatu Bellagio (Studi Pada Konsumen Toko Sepatu Bellagio Java Supermall Semarang). Doctoral Disertaton. Universitas Diponegoro.

Erdoğmuş, İ., \& Büdeyri-Turan, I. (2012). The role of personality congruence, perceived quality and prestige on ready-to-wear brand loyalty. Journal of Fashion Marketing and Management: An International Journal, 16, 399-417.

Kotler, P. \& Armstrong, G. (2012). Prinsip- Prinsip Pemasaran. Edisi 12 penerbit Erlangga, Jakarta.

Kotler, P. (2000). Prinsip - Prinsip Pemasaran Manajemen, Jakarta: Prenhalindo.

Kotler, P., \& Armstrong, G. (2001). Prinsip-prinsip Pemasaran. Alih Bahasa Imam Nurmawan. Erlangga, Jakarta.

Kotler, P., \& Amstrong, G. (2005). Principle of Marketing. New Jersey. Printice-Hall.

Kotler, P., \& Armstrong, G. (2008). Prinsip-prinsip Pemasaran. Edisi 12. Jilid 1. Jakarta: Erlangga.

Kotler, P., \& Keller, K. (2007). Manajemen Pemasaran, Jilid I, Edisi Kedua belas, PT. Indeks, Jakarta.

Kotler, P., \& Keller, K. (2009). Manajemen Pemasaran. Jilid I. Edisi ke 13 Jakarta: Erlangga.

Sugiyono. (2005). Metode Penelitian Kualitatif. Bandung: Alfabeta.

Sugiyono. (2010). Metode Penelitian Pendidikan Pendekatan Kuantitatif, kualitatif, dan RED. Bandung: Alfabeta

Sugiyono. (2018). Metode Penelitian Manajemen. Bandung: Alfabeta.

Swasta, B., \& Handoko, T. H. (2000). Manajemen Pemasaran dan Analisa Perilaku Konsumen. Edisi Pertama, Cetakan Ketiga, Penerbit: BPFE.

Swasta, B., Dharmesta, \& Irawan. (2008). Manajemen Pemasaran Modern. Yogyakarta: Liberty.

Vigneron, F., \& Johnson, L. W. (1999). A review and a conceptual framework of prestigeseeking consumer behavior. Academy of marketing science review, 1(1), 1-15. 